\title{
Теология в принятии управленческих решений
}

\author{
Давид Рахимов \\ Православный Свято-Тихоновский гуманитарный университет, Россия \\ ORCID 0000-0002-4554-9772 \\ rakhimov-t@mail.ru \\ D. Rakhimov, Theology in Management Decision Making, Elpis, 23 2021: 41-46. \\ D. Rakhimov, Teologia w podejmowaniu decyzji zarządczych, Elpis, 23 2021: 41-46
}

\begin{abstract}
Management decisions are always based on a set of non-random options. Each option is spiritual in nature. Faced with uncertainty, a person makes his choice not from random alternatives, but within the framework of the situation presented to him by God. In fact, a person makes his choice between virtue and passion, good and evil.
\end{abstract}

Streszczenie: Decyzje dotyczące zarządzania są zawsze podejmowane na podstawie zestawu nieprzypadkowych alternatyw. Każda opcja ma charakter duchowy. W obliczu niepewności człowiek wybiera nie przypadkowe alternatywy, ale w ramach sytuacji, którą zaoferował mu Bóg. W istocie człowiek dokonuje wyboru między cnotą a pasją, dobrem a złem.

Аннотация: Управленческие решения всегда принимаются из набора неслучайных альтернатив. Каждый вариант имеет духовный характер. Столкнувшись с неопределенностью, человек выбирает не из случайных альтернатив, а в рамках той ситуации, которую предложил ему Бог. По сути своей, выбор человек осуществляет между добродетелью и страстью, добром и злом.

Keywords: management, decision-making, change management

Słowa kluczowe: zarządzanie, podejmowanie decyzji, zarządzanie zmianą

Ключевые слова: менеджмент, принятие решений, управление изменениями

\section{cc) (i) ()}

\section{Введение}

Теория управления занимает важное место в экономическом учении. Предметом теории управления в политэкономии считается построение моделей для практической деятельности руководителей организаций. Теория разделяет процесс управления на планирование, организацию, контроль и координацию действий участников.

По мнению автора, теория управления, опираясь на парадигму, не учитывающую духовную основу нашего мира, формирует фрагментарное мышление, не позволяя тем самым воспринять все аспекты, влиянию которых подвержены как руководители, так и организация в целом. Без понимания взаимозависимости духовного и материального миров умопостроения, сколь бы логичными они ни казались, будут неполными и, следовательно, неверными. Значителен перечень нереализованных людских идей, безрезультатно израсходованных ресурсов, напрасно растраченного времени, внезапных поражений.

Автор предлагает на примере одного из частных случаев теории управления, учения об управлении изменениями, рассмотреть некоторые богословские суждения, в результате чего будет выявлена сторона, не учитываемая теорией, но оказывающая значимое влияние на процесс принятия решений. Читателю, не знакомому с учением управления изменениями, пред- лагается составить о нем представление на основании некоторых его положений.

Предметом учения об управлении изменениями указаны методы перевода организаций из текущего состояния в некое желаемое будущее состояние, учитывающие при этом воздействие управляющей системы не только на саму себя, но и на внешнюю среду в связи с изменениями (переменами) внутри системы. Таким образом, учением формируются не только способы воздействия субъекта на управляемый объект, но и методы, изменяющие объект, например, его привычки и состояние. Предлагаемый учением инструментарий широк, и включает в себя как математические, так и психологические решения.

Например, одним из рецептов управления изменениями является метод «восьми шагов» (Kotter, 2014), предлагающий следующие действия (Kotter, 2014).

1. Внушение людям ощущения необходимости перемен.

2. Создание влиятельной команды реформаторов, агентов перемен.

3. Создание видения (образа) желаемого будущего с целью повышения активности сотрудников.

4. Пропаганда нового видения.

5. Внесение изменений в структуру организации, устранение блокирующих препятствий, противоречащих новому видению.

6. Получение быстрых результатов и их пропаганда. 
7. Закрепление достигнутых успехов и углубление перемен, создание атмосферы доверия к новым подходам, смена кадрового состава и кадровые перестановки.

8. Укоренение изменений в корпоративной культуре, формализация правил поведения.

Таким образом, учение убеждает, что стимулированием выхода организации из состояния внутреннего равновесия запускается механизм достижения желаемого развития. Необходимость изменений системы, по мнению учения, побуждается некими макроэкономическими силами, под воздействием которых организации вынуждены непрерывно искать новые возможности для роста, сокращать издержки, повышать производительность, улучшать качество сервиса. При этом отмечается, что это влияние особенно усилилось в последние десятилетия.

В учении об управлении изменениями мир представляет собой нестабильную, неустойчивую и непрерывно эволюционирующую систему. В развитии мира спокойный этап поступательных изменений по некой причине сменяется периодом обострения сверхбыстрым нарастанием изменений, и действовавший ранее детерминизм событий трансформируется в случайность. Таким образом, по учению, в точках бифуркации ${ }^{1}$ действует случайность, между точками бифуркации - детерминизм. При этом периоды устойчивости и равновесия системы указываются как тупики эволюции. Неустойчивость, происходящая от случайности, утверждается источником развития мира. В точках бифуркации руководитель выбирает из сформировавшихся случайным образом альтернатив.

Хаос, с одной стороны, представляется разрушительным, с другой принимается конструктивным и созидательным. Полагается, что хаос имеет локальную природу, он возникает и присутствует в рамках неких тенденций развивающейся более глобальной системы. То есть развитие представляется как последовательность кратковременно упорядоченных периодов в русле хаотичного или вероятностного поведения мира при некой внешней стабильности. Иными словами, мир как бы еще находится в состоянии выбора пути дальнейшего своего развития. В таком мире системы самопроизвольно возникают, относительно устойчиво существуют и затем саморазрушаются.

В учении различаются процессы организации и самоорганизации. Для процесса организации характерно внешнее линейное руководящее влияние на систему. В случае самоорганизации упорядоченность восстанавливается за счет неких внутренних свойств подсистем, входящих в систему, с одновременным воздействием на нее также и со стороны внешней среды. То есть утверждается, что система может самостоятельно самоупорядочиться, когда она без видимого воздействия

\footnotetext{
Точкой бифуркации называют критический момент, точку разветвления вариантов развития системы. Предсказать дальнейшее направление в развитии системы в этот момент невозможно. В этой точке системой избирается некая траектория движения.
}

на нее извне обретает некую гармоничную функциональную структуру. Это самоупорядочивание происходит несмотря на внешнюю спонтанность и отсутствие видимого детерминизма в поведении подсистем и самой системы. При этом отмечается, что процессы, переводящие систему в новое состояние, могут наблюдателю сначала представляться не благоприятными, но затем часто оцениваются им как полезные.

Согласно учению, внешняя среда лишь инициирует определенные потенциальные изменения внутри самой системы. Поэтому управляющее воздействие на систему будет эффективным, только если оно согласовано с внутренними свойствами этой системы, чтобы стать для нее резонансным. При этом итог смены состояний в значительной степени определяется взаимосвязями во внутренней структуре, а не силой внешнего воздействия. Например, некая творческая идея, возникшая случайно, способна явиться толчком для сохранения или же разрушения системы. То есть под воздействием вроде бы незначимых факторов внешне устойчивая организация может резко изменить свое состояние. Поэтому, по учению, даже непривычный, казалось бы, отказ от тщательного планирования свобода творчества, оригинальная идея - могут стать источником самосохранения организации и ресурсом ее дальнейшего развития. Следовательно, ни одна организация не может быть уверена в собственной устойчивости, благоприятное состояние дел является преходящим. Любой период благоприятного состояния следует воспринимать лишь как промежуточное состояние в эволюционном процессе обновления. Таким образом, устойчивость организации зависит от умения перестраиваться, отвечая поставленным целям, иначе ей грозит гибель.

Учением также отмечается одна из особенностей, присущая системам, а именно необратимость процесса самоорганизации. Спровоцированные в системе изменения сами не подавляются, а накапливаются и усиливаются. Попытки преодолеть активность самоорганизации воздействием извне сталкиваются с невозможностью изменить направленность процессов самообразования в каждый определенный момент. Процесс самоорганизации системы противодействует сознательному руководству, протекая по неким «собственным» законам.

Согласно учению, наличие в системе противоречий является нормальным для ее развития. К таковым в деловой среде относят противоречия между предпринимателями и наемными работниками, владельцами бизнеса и менеджерами, потребителями и производителями, предпринимателями и органами государственного контроля. В то же время учением отмечается, что внутренние противоречия могут привести к ослаблению бизнеса вплоть до его полного разрушения.

Для успешной деятельности, согласно учению, руководитель должен обладать такими качествами, как лидерство, жажда успеха, напористость, агрессивность, уверенность в своих силах в ситуациях соперни- 
чества, умение работать в турбулентной бизнес-среде. Утверждается, что эти качества необходимы руководителю, чтобы удовлетворять личным, «законным» желаниям. Увеличивая объем знаний, человек способен управлять возрастающей неустойчивостью мира. Правильный сознательный подбор инструментов управления гарантирует руководителю однонаправленное развитие организации в сторону процветания и увеличения объемов прибыли. В конкурентной борьбе гибнут лишь слабые и наименее рационально организованные предприятия.

Вместе с тем, предлагая систему управления, учение с сожалением констатирует, что формирование полного набора управленческих решений в ответ на возможные изменения состояний внешней среды невозможно, нередко процессы оказываются неуправляемыми (одним из примеров таких безуспешных усилий являлась попытка внедрить японские кружки качества в США и Западной Европе). Наблюдаемое число состояний даже небольшой фирмы столь велико, что попытки выработать алгоритм и полностью автоматизировать процесс управления оказываются тщетными. Зачастую руководителю остается доступной лишь возможность предвидеть отдельные фрагменты будущего развития предприятия. Следовательно, стратегическое управление не является сегодня панацеей гарантии успешности предприятия. Шансы выжить у организаций, действующих в соответствии с четкой стратегией и не имеющих таковой, практически равны. Таким образом, учение приходит к противоречивому выводу: ключевым ресурсом, позволяющим предприятиям успешно функционировать на протяжении длительного времени без стратегического плана, оказывается не агрессивное и активное поведение, а способность поддержания равновесия со своим окружением.

Для дальнейшего обсуждения философский базис учения об управлении изменениями можно, по мнению автора, привести к следующим его утверждениям:

- развитие мира идет посредством хаоса и случайностей;

- в природе существуют системы, способные самоорганизовываться;

- выбор человека состоит из так называемых «случайных альтернатив».

Переходя к богословской оценке утверждений учения об управлении изменениями, напомним, что в каждом принимаемом руководителем решении не только содержится опыт управленца, но и отражается его мировоззрение. Не всякий способ решения проблемы находит солидарность в душе, иной отвергается, несмотря на внешнюю рациональную привлекательность.

\section{1. О хаосе и случайностях}

Христианское вероучение отвергает существование хаоса и случайностей, утверждая, что мир сотво- рен Богом разумно и развивается в полном соответствии с Его замыслом. Ничто и никто не существует в мире вопреки Его плану: «Все через Него начало быть, и без Него ничего не начало быть, что начало быть» (Bibliâ. Russkij sinodal'nyj perevod, 2003, Ин. 1:3). Во всем творении присутствует порядок и мера, нет ничего недостающего и ничего избыточного, Бог все «расположил мерою, числом и весом» (Bibliâ. Russkij sinodal'nyj perevod, 2003, Прем. 11:21) и определил всему место и время (Bibliâ. Russkij sinodal'nyj perevod, 2003, Еккл. 3:1-2).

Библейское повествование дает нам примеры Божьего планирования и исполнения. Сказал Бог земле произвести «траву, сеющую семя и дерево плодовитое... И стало так» (Bibliâ. Russkij sinodal'nyj perevod, 2003, Быт. 1:11). Все сотворенное Богом есть «хорошо весьма» (Bibliâ. Russkij sinodal'nyj perevod, 2003, Быт. 1:31). Священное Писание раскрывает нам Божьи планы и на будущее человечества, которые, по христианской вере, однозначно осуществятся. Слово Его всегда исполняется: «...слово Мое ... не возвращается ко мне тщетным, - говорит Господь, - но исполняет то, что Мне угодно, и совершает то, для чего Я послал его» (Bibliâ. Russkij sinodal'nyj perevod, 2003, Ис. 55:11).

И грехопадение Адама в раю не было для Бога случайностью. Решение о спасении человека было принято Богом еще до сотворения человека: «Не только то Бог предвидел, что Адам согрешит, но и то, что падшего Он восставит посредством домостроительства» (Makarij Bulgakov, 1883, с. 125). Предвидя падение человека, Бог прежде сотворил из ребра Адама жену, помощницу, подобную ему, чтобы род человеческий после преступления сохранился посредством размножения людей.

Хотя человек был изгнан из рая, однако Господь не оставил Своего попечения о человеке и мире. Человеческая история развивается в русле границ, определенных Богом, по Его плану, ибо «все от Него, Им и к Нему» (Bibliâ. Russkij sinodal'nyj perevod, 2003, Рим. 11:36). Как уточняет преподобный Иоанн Дамаскин (Ioann Damaskin, 1992), «Бог все предвидит, но не все предопределяет». Бог предвидит все, что находится в человеческой власти, но не понуждает человека, имея готовое решение на каждый его выбор. Все решения человека известны Богу. Пророк Давид обнаруживает, что Бог ведает все помышления человека: «Еще нет слова на языке моем, - Ты, Господи, уже знаешь его совершенно» (Bibliâ. Russkij sinodal'nyj perevod, 2003, Пс. 138:4). Каждый выбор человека укладывается в Божий план, который в полном объеме охватывает жизнь не только отдельного человека, но и народа, мира и всего бытия.

Завершим эту часть исследования словами архимандрита Иоанна Крестьянкина (цит. по Orlova, 2016): «Случайностей в жизни нет и быть не может, Бог-Промыслитель правит миром, и каждое обстоятельство имеет высший духовный смысл». 


\section{2. О самоорганизующихся системах}

Христианское вероучение указывает, что Господь осуществляет Свое попечение о мире непрерывно. Природа подчиняется Божьей воле, исполняя установленные Им законы. Бог дал приказание утру и указал заре ее место, Им даны уставы небу, Его слова слушаются облака и молнии, Он ловит добычу львице (Bibliâ. Russkij sinodal'nyj perevod, 2003, Иов. 38) и питает птиц небесных, которые сами не сеют и не жнут (Bibliâ. Russkij sinodal'nyj perevod, 2003, Мф. 6:26).

Из земных творений лишь человек получил от Бога дар принимать решение, преобразовывать природу Божью и организовывать себе подобных, то есть самоорганизовываться. Бог, даровав человеку свободу воли, тем как бы умалил Свое всемогущество для проявления выбора человека. Вселенная существует по Божьей воле, во всем присутствует гармония, планеты движутся установленным Им путем, солнце согревает в свое время, Его волей организованы колонии муравьев и пчел. Лишь в человеческом обществе постоянно возникают неустройства по причине неразумного пользования даром свободы. Поэтому Бог, предвидя заранее будущее произволение воли падшего человека, попускает воле его иметь столько силы, сколько полезно душе действующего и воспринимающего. Господь не попустит влияния одного человека на другого сверх допущенного Им.

Священное Писание указывает, что устойчива будет лишь та организация, которую охранит Бог. Без Бога собрание людей никогда бы не приняло форму общества, оно быстро было бы разрушено внутренними страстями. Это была бы группа индивидов, отрицающих любую социальную иерархию. Об этом говорит пророк: «Если Господь не созиждет дома, напрасно трудятся строящие его; если Господь не охранит города, напрасно бодрствует страж» (Bibliâ. Russkij sinodal'nyj perevod, 2003, Пс. 126:1).

Итак, завершая исследование второго утверждения теории, повторим, что из земных творений самоорганизовываться может лишь человек, прочие творения организуются Богом, непрерывно осуществляющим промысл о мире.

\section{3. О «случайных» альтернативах выбора}

Христианское вероучение утверждает, что весь мир существует волей Божьей, случайностей нет. Столкнувшись с неопределенностью, человек выбирает не из случайных альтернатив, а из того, что предложил ему Бог: «...жизнь и смерть предложил я тебе, благословение и проклятие. Избери жизнь» (Bibliâ. Russkij sinodal'nyj perevod, 2003, Втор. 30:19). Каждое обстоятельство имеет высший духовный смысл, и, по сути своей, выбор человек осуществляет между добродетелью и страстью, добром и злом.

Святоотеческое Предание учит, что человек при выборе решений не одинок, мысли его имеют три источника: от Бога, от себя и от бесов. Мысли от Бога всегда истинны и спасительны. Мысли о себе естественны и ограничены лишь личным опытом. Помыслы от бесов разрушительны, они противоположны тому, что желает Бог и несут в себе опасность как для лица, принимающего решение, так и для других людей. Конечная цель бесовских помыслов - погубить человека, бес «сам же вложит мысль греховную в душу человека, да тут же и запишет ее, как его собственную, дабы впоследствии на Страшном Суде Божием обвинить человека» (Амвросий Оптинский, цит. по Kandalincev, 2010). Враг подбрасывает ему перечень аргументов, ища слабые стороны в нравственной защите человека, чтобы добиться своего. Помыслы от дьявола зовут человека в мир плотских наслаждений: власти, удовольствий, представляя все это привлекательным. Но бесы скрывают, что предлагаемый ими мир обманчив, удовольствия скоротечны и не дают утешения, подталкивая человека к ненасытности. Томление и мучения совести, возникающие по принятии решения, являются сигналом о выборе человеком бесовского совета. Путаница и противоречия в мыслях нередко вызываются прямым воздействием беса. «...Вся эта противоречащая путаница есть действие врага, который борет и десными [справа] и шуими [слева], то тоскою и страхом, то высокоумием и самонадеянностью», - наставляет преподобный Амвросий Оптинский (Kandalincev, 2010).

Действия беса разнообразны и настырны, он имеет множество уловок и готов вновь и вновь льстить человеку. Бес с помощью навязываемых помыслов стремиться уловить душу человека. Грешные помыслы горделивого ума получают простор для развития: забрать или принудить силой, подкупить, осудить, полагать себя более осведомленным, оправдываясь тем, что «...я не таков, как прочие люди, грабители, обидчики, прелюбодеи» (Bibliâ. Russkij sinodal'nyj perevod, 2003, Лк. 18:11). Внутреннее несогласие с греховными мыслями, их неприятие указывает, что они пришли от бесов. Бог попускает атаку дьявола на ум человека, чтобы человек увидел устроение своей души и понял, с кем он солидарен. Какой бы рациональной ни казалась идея, если она противоречит нравственной установке (а для христиан это заповеди и установления Божьи), такую мысль следует отвергнуть. Господь предупреждает: «...какая польза человеку, если он приобретет весь мир, а душе своей повредит?» (Bibliâ. Russkij sinodal'nyj perevod, 2003, Мф. 16:26). Страсти создают противоречия в обществе людей и ведут к разрушению организации. Проявлениями этих страстей являются неподчинение властям, высокое самомнение, осуждение других, сквернословие, безответственность, некачественная сумбурная работа, зависть к успехам других. 
Подводя итог обсуждению тезиса о «случайности» выбора, повторим, что человек делает выбор не из случайных альтернатив, а избирает между познанием Бога и Его отрицанием. Несмотря на глубокое падение современного человека, отметим, что Богоданная добродетель еще действует в его сердце. Его душе ближе не борьба за существование, а взаимопомощь, сотрудничество и жертвенность.

\section{Заключение}

Христианское вероучение указывает, что ситуации, в которых оказывается человек или группа людей, не случайны, они возникают в зависимости от прошлых деяний и личного предназначения каждого. Порою связь очевидна: ты украл - у тебя украли, ты угнетал - тебя принудили. Господь попускает до времени событиям следовать воле страстного человека, чтобы выбор стал очевидным для него самого. Позднее Бог ставит грешника в такую ситуацию, в которой он ощутит на себе зло, кое ранее совершил сам. Бог подводит грешника к зеркальной ситуации не сразу, а спустя некоторое время. Как сеяние отстоит от жатвы, так и назидание Божие следует после созревания души грешника, чтобы лучше усвоился урок Господний. «Не обманывайтесь: Бог поругаем не бывает. Что посеет человек, то и пожнет», - предупреждает апостол Павел (Bibliâ. Russkij sinodal'nyj perevod, 2003, Гал. 6:7).

Когда наступит срок, Господь сдержит развитие организации, и сообщество человеческое сразу испытает на себе давление, как «давит колесница, нагруженная снопами» (Bibliâ. Russkij sinodal'nyj perevod, 2003, Ам. $2: 13)$, как будто весь мир восстал против. События выстраиваются в череду непрерывных потерь от действий конкурентов и надзорных государственных органов, как если бы они скрытно объединились. Против такого давления действия людей оказываются бессильны. Новая ситуация становится «толчком» будущего преобразования, посредством которого проявятся страсти, сокрытые в сердце каждого члена коллектива. В такие моменты система приходит в движение, Господь выводит ее на иной уровень, выше или ниже, соответствующий ее месту в истории всего человечества: «Господь делает нищим и обогащает, унижает и возвышает» (Bibliâ. Russkij sinodal'nyj perevod, 2003, 1Цар. 2:7).

Противиться Божьему решению человек не способен, как не может сырой глиняный горшок противиться горшечнику. В такие моменты особое значение приобретают терпение, взаимопомощь, согласованность и сотрудничество, а не «война всех против всех». Христианское вероучение утверждает, что человек планирует и действует, но свершится лишь то, что дозволит Бог: «В полу бросается жребий, но все решение его - от Господа» (Bibliâ. Russkij sinodal'nyj perevod, 2003, Прит. 16:33).

Священное Писание указывает, что особые требования предъявляются Богом к царям народов. Так, например, пока царь Давид правильно поступал перед лицом Бога, то всякая битва была вместе с тем и победой. И пока царь Иоас «делал угодное в очах Господних» (Bibliâ. Russkij sinodal'nyj perevod, 2003, 4Цар. 12:2), царство его пребывало в мире, но как только отступил Иоас от Господа, стал служить идолам, сразу подверглось его царство нападению сирийцев, которых Бог избрал для назидания всего общества и царя Иоаса (Bibliâ. Russkij sinodal'nyj perevod, 2003, 4Цар. 12).

Страдания народа за грех правителя не означает, что он более грешен, чем его народ, или Бог несправедлив. Все начинается с греха народа, действия царя лишь отражают духовное состояние народа (Bibliâ. Russkij sinodal'nyj perevod, 2003, 2 Цар. 24:1). «Нечестивым же нет мира, говорит Господь» (Bibliâ. Russkij sinodal'nyj perevod, 2003, Ис. 48:22). В то же время ради добродетелей царя Господь дарует всему обществу мир и «покой от всех врагов его кругом» (Bibliâ. Russkij sinodal'nyj perevod, 2003, 1Пар. 22:9). Начальники, чтящие Бога, самою жизнью своей обеспечивают мир и преуспеяние в делах организации.

Библия также учит, что не принесет пользу организации и союз с теми, кто делает «неугодное в очах Господних». При заключении союза должны иметь главенствующее значение не материальная мощь, производство или денежные средства, а духовные и моральные качества общества будущего партнерства. Беззаконный партнер навлекает беду и на себя, и на своих союзников. В Библии мы видим немало примеров, подтверждающих, что союз со злым приносит зло. Так, например, царь Охозия заключил союз с нечестивым и беззаконным Иорамом. Результатом неудачного объединения военных сил стала не только проигранная Сирии война, но и гибель самого царя Охозии (Bibliâ. Russkij sinodal'nyj perevod, 2003, 4Цар. 9:27).

Христианская Церковь со скорбью отмечает, что, пребывая в мире и изобилии, люди становятся безбожными и эгоистичными. Вместо Бога в центре оказывается личное «я», обычным становится идолопоклонство, себялюбие и неразборчивость в средствах. Как невозможно построить крепкий дом без фундамента, так и решения человеческие становятся ущербными, когда исключена Основа. Люди восстают против Бога, и это влечет за собой беспорядки, кризисы и, «как венец всего, войну» (Nikolaj Serbskij, 2016), как единственное верное средство отрезвления народа. Пророк предупреждает, что Бог судится «со всякой плотью» (Bibliâ. Russkij sinodal'nyj perevod, 2003, Иер. 25:31), и наиболее возгордившиеся перед Ним окажутся наиболее пострадавшими.

Назидание Божье неотвратимо, хотя и долго назревает, то «приближая, то отдаляя момент своего начала» (Nikolaj Serbskij, 2016). Наступает момент, и вот малозначимое действие становится толчком изменений в организации. Святитель Николай (Nikolaj Serbskij, 2016) отмечает, что часто «Бог употребляет, на человеческий взгляд, незначительные средства, чтобы поразить гордых и неверующих». Простое поднятие рук избранником Божьим поражает сильного врага в бою 
(Bibliâ. Russkij sinodal'nyj perevod, 2003, Исx. 17:11), звук труб разрушает стены города (Bibliâ. Russkij sinodal'nyj perevod, 2003, Нав. 6:19).

Христианское вероучение воспринимает противоречия в обществе, восхваляемые наукой, как неполезное разделение. Таковое разделение разрушает здоровое тело общества и вредит, в первую очередь, самим спорщикам. Священное Писание учит, что в обществе в главном важно хранить единство, во второстепенном допустимо разномыслие, чтобы «открылись... искусные» (Bibliâ. Russkij sinodal'nyj perevod, 2003, 1Кop. 11:19), и во всем должна присутствовать любовь. Без любви нет никакой пользы от разномыслия. Евангелие раскрывает нам, что только благодаря любви и поддержанию мирных отношений сохраняется устойчивость организации, потому что «Бог не есть Бог неустройства, но мира» (Bibliâ. Russkij sinodal'nyj perevod, 2003, 1Кор. 14:33).

Священное Писание дает нам пример того, как принимать управленческое решение: «...вы, говорящие: «сегодня или завтра отправимся в такой-то город, и проживем там один год, и будем торговать и получать прибыль»; вы, которые не знаете, что случится завтра: ибо что такое жизнь ваша? пар, являющийся на малое время, а потом исчезающий. Вместо того чтобы вам говорить: «если угодно будет Господу и живы будем, то сделаем то или другое»») (Bibliâ. Russkij sinodal'nyj perevod, 2003, Иак. 4:13-15). Человеку, склоняющему свою волю к воле Божьей, Господь дает Свою помощь: «...ибо Я Господь, Бог твой; держу тебя за правую руку твою, говорю тебе: «не бойся, Я помогаю тебе» (Bibliâ. Russkij sinodal'nyj perevod, 2003, Ис. 41:13). Когда «Бог посреди» (Bibliâ. Russkij sinodal'nyj perevod, 2003, Пс. 45:6), тогда все гармонично и устойчиво.

Возможно, автору возразят, что не все народы исповедуют христианство и веруют в единого Бога, есть народы, придерживающиеся иных верований. Значит ли это, что установления Бога не распространяются на них? На это Священное Писание дает ответ: как солнце светит для всех, так и законы Божьи касаются всех людей, верующих и неверующих. Для христиан значимость имеет их отношение к Богу и Его закону, явленному через Иисуса Христа; для нехристиан значение имеет следование закону, записанному у них в сердцах, «о чем свидетельствуют совесть их и мысли их, то обвиняющие, то оправдывающие одна другую» (Bibliâ. Russkij sinodal'nyj perevod, 2003, Рим. 2:15). Бог нелицеприятен и «во всяком народе боящийся Его и поступающий по правде приятен Ему» (Bibliâ. Russkij sinodal'nyj perevod, 2003, Деян. 10:35).

\section{Библиография}

Avva Dorofej, prp. (2010). Dušepoleznye poučeniâ i poslaniâ. Poučenie 12. O strahe buduŝsego mučeniâ i o tom, čto želaûsij spastis' nikogda ne dolžen byt' bespečen o svoem spasenii. Blagovest. [online] https://azbyka.ru/otechnik/Dorofej/dushepoleznye-pouchenija-i-poslanija/, [11.02.2021].

Bibliâ. Russkij sinodal'nyj perevod (2003). [online] https://bibleonline.ru/bible/rst78/gen/, [11.02.2021].

Grigorij Bogoslov, svt. (2010). Tolkovanie na Byt. 1:31: Tolkovaniâ Svâŝennogo Pisaniâ. Vvedenskij mužskoj stavropigial'nyj monastyr' Optina Pustyn'. [online] http://bible.optina.ru/ old:gen:01:31\#svt_grigorij_bogoslov, [11.02.2021].

Ivanova, T. Û. i Prihod'ko, V. I. (2006). Teoriâ organizacii. KnoRus. [online] https://may.alleng.org/d/manag/man169.htm, [11.02.2021].

Ioann Damaskin, prp. (1992). Točnoe izloženie pravoslavnoj very. Priazovskij kraj. [online] https://azbyka.ru/otechnik/ Ioann_Damaskin/tochnoe-izlozhenie-pravoslavnoj-very/, [11.02.2021].

Ioann Zlatoust, svt. (1906). Beseda 1. O lûbvi: Vyborki iz raznyh slov svâtogo Ioanna Zlatousta (tom 12, kniga 2). Izdanie SPB. Duhovnoj Akademii. [online] https://azbyka.ru/otechnik/Ioann_Zlatoust/vyborki/1, [11.02.2021].

Ioann Tobol'skij (Maksimovič), svt. (2014). Iliotropion ili soobrazovanie čelovečeskoj voli s volej Božestvennoj (3 izd.). Izdatel'stvo Sretenskogo monastyrâ. [online] https://azbyka. ru/otechnik/Ioann_Tobolskij/iliotropion/, [11.02.2021].

Isaak Sirin, prp. (2008). Slovo dvadcat' pervoe: Slova podviž- nečeskie. Svâto-Troickaâ Sergieva Lavra. [online] https:// azbyka.ru/otechnik/Isaak_Sirin/slova-podvizhnicheskie/21, [11.02.2021].

Kandalincev, V. (2010). Gl. 6. Pravila bor'by spomyslami: Učenie optinskih starcev. OOO 'IPC 'Maska'. [online] https:// azbyka.ru/otechnik/prochee/uchenie-optinskih-startsev/6_2, [11.02.2021].

Kotter, Dž. P. (2014). Vperedi peremen. Olimp-biznes. [online] https://baguzin.ru/wp/wp-content/uploads/2015/01/ДжонП.-Коттер.-Впереди-перемен.pdf, [11.02.2021].

Koževina, O.V. (2012). Upravlenie izmeneniâmi: učebnoe posobie. Infa-M. [online] http://padaread.com/?book=101372 $\& p g=3,[11.02 .2021]$.

Makarij (Bulgakov), mitr. (1883). Pravoslavno-dogmatičeskoe Bogoslovie. (t. 1). Tip. R. Golike. [online] https://azbyka. ru/otechnik/Makarij_Bulgakov/pravoslavno-dogmaticheskoe-bogoslovie-tom1/, [11.02.2021].

Nikolaj Serbskij, svt. (2016). Vojna i Bibliâ. Rodnoe slovo. [online] https://azbyka.ru/otechnik/Nikolaj_Serbskij/vojna-i-biblija/, [11.02.2021].

Orlova, A. (2016). «Lučše po krohamučastvovat' v sozidanii, čem odnim mahom razorât'» — sil'nye citaty starca Ioanna (Krest'ânkina). Foma. [online] https://foma.ru/arhimandrit-ioann -krestyankin-aforizmyi.html, [11.02.2021].

Rampersad, H. (2004). Universal'naâ sistema pokazatelej. Al'pina Biznes Buks. [online] https://pqm-online.com/assets/ files/lib/books/rampersad3.pdf, [11.02.2021].

Rozmiar artykułu: 0,8 arkusza wydawniczego 